TITLE:

\title{
Atmospheric pressure waves and tectonic deformation associated with the Alaskan earthquake of March 28
}

\author{
$\operatorname{AUTHOR}(\mathrm{S})$ : \\ Mikumo, Takeshi
}

\section{CITATION:}

Mikumo, Takeshi. Atmospheric pressure waves and tectonic deformation associated with the Alaskan earthquake of March 28. Journal of Geophysical Resesrch 1968, 73(6): 20092025

ISSUE DATE:

1968-03-15

URL:

http://hdl.handle.net/2433/193377

RIGHT:

Copyright 1968 by the American Geophysical Union. 


\title{
Atmospheric Pressure Waves and Tectonic Deformation Associated with the Alaskan Earthquake of March 28, 1964
}

\author{
Takeshi Mikumo
}

\author{
Disaster Prevention Research Institute, Kyoto University, Kyoto, Japan
}

\begin{abstract}
Atmospheric pressure disturbances with periods as long as 14 min have been recorded by sensitive microbarographs at five stations along the Pacific coast and at a station in Alaska after the great Alaskan earthquake of March 28, 1964. The phase and group velocities of the disturbances are consistent with those so far observed in atmospheric nuclear explosions and with theoretical dispersion curves for acoustic-gravity waves. These velocities and field observation of the tectonic deformations in the epicentral region suggest that the pressure disturbances might have been caused by the rapid vertical ground displacement at the source area. Theoretical barograms appropriate to the Berkeley station have been constructed on the basis of reasonable estimates for the source dimension, the amount of uplift and subsidence, and the time rate of the displacement, taking the atmospheric and instrumental responses into account. Agreement between general features of the observed and theoretical barograms appears sufficient to support the above generation hypothesis, suggesting a possible range for the time rate of the surface tectonic deformation.
\end{abstract}

\section{INTRODUCTION}

The great Alaskan earthquake of March 28, 1964 (03h $36 \mathrm{~m} 14.2 \mathrm{~s}$ GMT; $61.0^{\circ} \mathrm{N}, 147.7^{\circ} \mathrm{W}$, $M=8.5$ ), was accompanied by large tectonic deformations with uplift and subsidence of the ground over an epicentral region that extended for $170,000 \mathrm{~km}^{2}$ [Plafker, 1965]. It was first reported by Bolt [1964] that a sensitive microbarograph at Berkeley, $3130 \mathrm{~km}$ from the epicenter, had recorded atmospheric pressure waves with periods longer than $10 \mathrm{~min}$. This report was followed by a similar observation at $\mathrm{La}$ Jolla [Van Dorn, 1964]. Although Benioff and Gutenberg [1939] almost 30 years ago identified sound waves with periods shorter than 3 sec on microbarographs $670 \mathrm{~km}$ apart from an earthquake epicenter and although observations of air waves coupled to seismic Rayleigh waves had also been described earlier [Benioff et al., 1951], it does not appear that pressure waves of the type recorded after the Alaskan earthquake have been previously observed in relation to an earthquake. The only other atmospheric waves from natural sources that may be compared with the present case are those from the eruption of the volcano Krakatoa in 1883 and the fall of the great Siberian meteorite in 1908. On the other hand, pressure disturbances with long periods excited by nuclear detonations in the atmosphere have been recorded many times [Donn and Ewing, 1962; Donn and Shaw, 1967] by microbarographs over the globe since the first observation by Yamamoto [1955]. A comparison of the microbarograms at the time of the Alaskan earthquake with microbarograms of nuclear explosions reveals characteristic differences in the recorded wave forms. The prevailing hypothesis of the mechanism of generation is that the air waves may have been caused by a sudden vertical displacement or tilting of the ground near the center of the earthquake [Bolt, 1964], but the extended nature of the source could produce complicated wave forms because of the interferences of various kinds of waves.

The purpose of this paper is to test the validity of the hypothesis. A first step of the study is an application of the Fourier transform and digital filtering techniques to microbarograph records to determine the spectrum and the phase and group velocities of the pressure waves in comparison with those expected from theories and past observations of nuclear explosions. The second approach is to make appropriate assumptions on possible source mechanisms and then compute synthetic theoretical barograms from known parameters to compare them with the observed records. This paper is not concerned either with groundcoupled air waves or with ionospheric disturb- 
ances, which were also observed at several places during the Alaskan earthquake [Row, 1967].

\section{Observations}

Microbarograph records from more than twenty locations of U. S. and Canadian weather stations, universities, and laboratories in the western part of North America, including Hawaii, and of the Japan Meteorological Agency have been examined to see if atmospheric pressure waves of long periods were recorded after the earthquake. Pressure waves with a long duration can be undoubtedly identified on the microbarograms from College (Geophysical Institute, University of Alaska), Berkeley (Seismographic Station, University of California), La Jolla (Scripps Institution of Oceanography, University of California), and a tripartite network of Mission Beach, East San Diego, and Point Loma (U. S. Navy Electronics Laboratory), all except the first being on the Pacific coastal region of California. At the Berkeley, La Jolla, and Point Loma stations, two independent sets of the pressure records have been obtained. No definite evidence of the arrivals has been seen at other stations, including those of Japan (N. Murayama, personal communication, 1965). This absence might be due to lower sensitivity of the instruments used and partly due to prevailing atmospheric conditions and local topography. The original records from the above six stations are reproduced in Figures 1-4, and the location, epicentral distance, and other information are summarized in Table 1. It can be seen directly that the recorded wave forms, except for College, show a good consistency among these stations, although the time resolution is somewhat different. The pressure waves arrive as an apparent compression (upward on the records except Figures $3 b$ and $4 d$ ) followed by a large rarefaction with longer periods, on which short-period wave trains are superposed but specific onset times are rather hard to identify.

The arrival times of the first compression peak coherent on all the records are given in Table 1. The College record is so disturbed by large pressure oscillations, which may be due to the arrival of seismic waves, that it is almost impossible to identify an onset of pressure waves; the time indicated in the table has been only tentatively adopted as that of the corresponding peak by the aid of digital filtering. The time resolution at the tripartite stations around San Diego is, unfortunately, not precise enough to determine the phase velocity solely from the observations. If we assume that the source of the pressure waves is near the epicenter, the travel times of the first peak at College, Berkeley, La Jolla, and East San Diego, as shown in Figure 5, yield a phase velocity of $319.0 \mathrm{~m} / \mathrm{sec}$ from least squares, indicating a

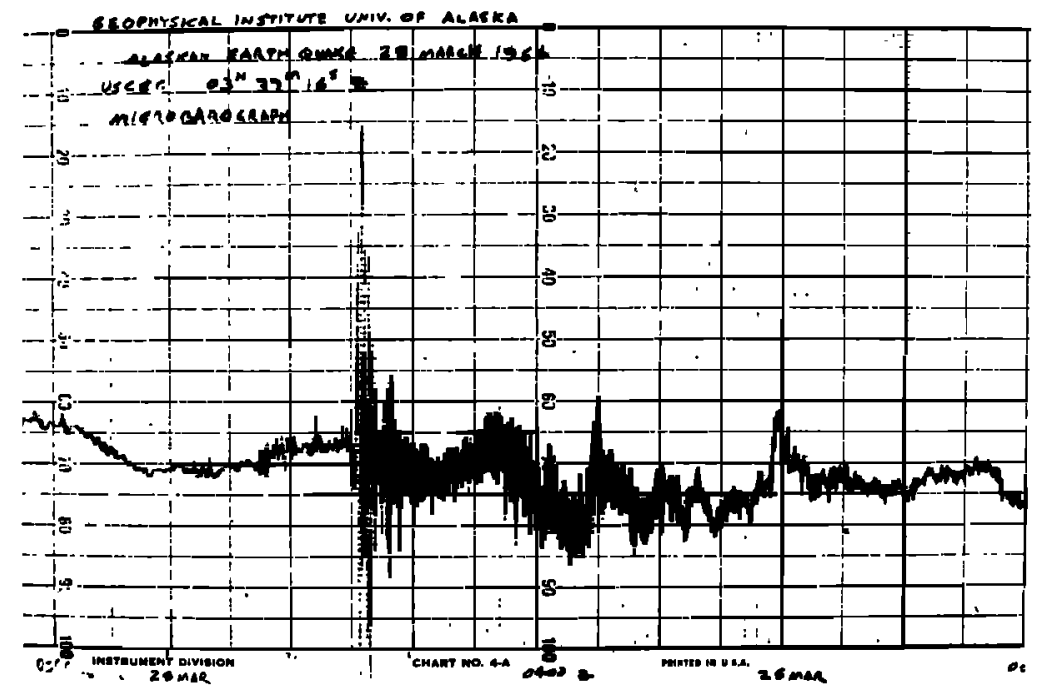

Fig. 1. Microbarogram recorded at College, Alaska (provided by E. Berg). The maximum double amplitude of the long-period waves is about $120 \mu \mathrm{bar}$. 


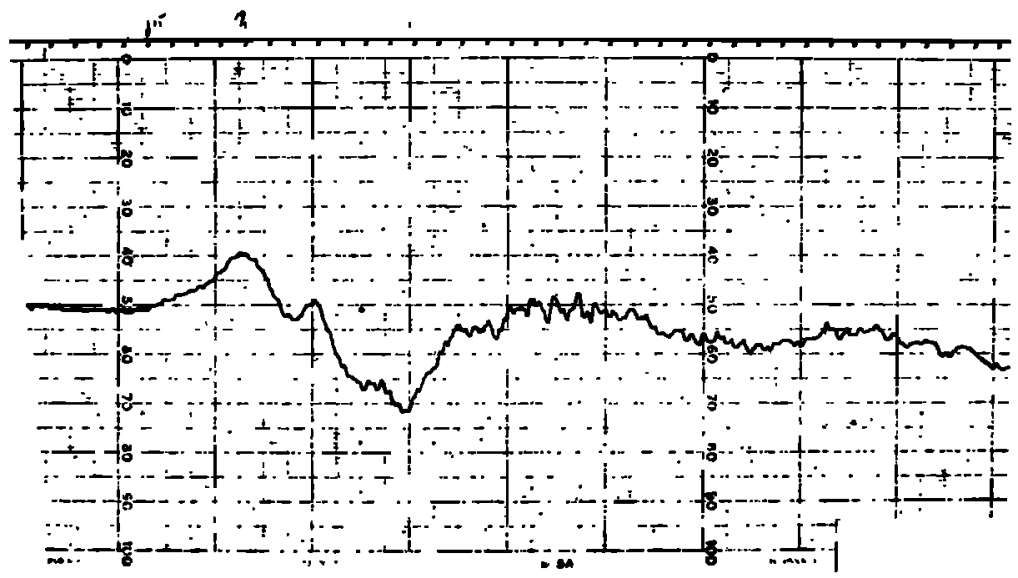

Fig. 2. Microbarogram recorded at Berkeley, California. The maximum double amplitude is about $40 \mu \mathrm{bar}$.

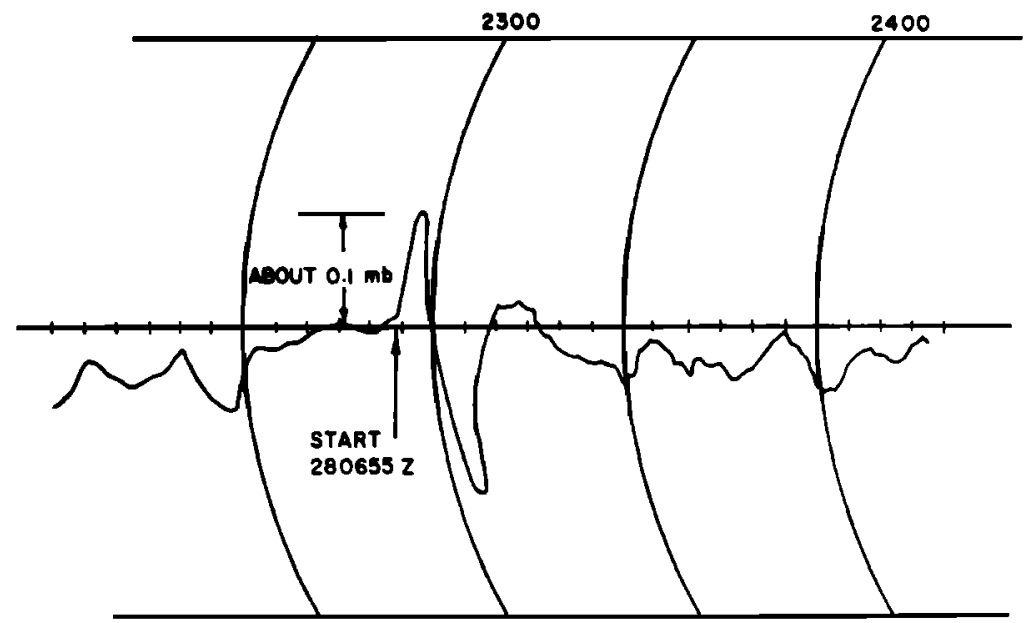

Fig. $3 a$.

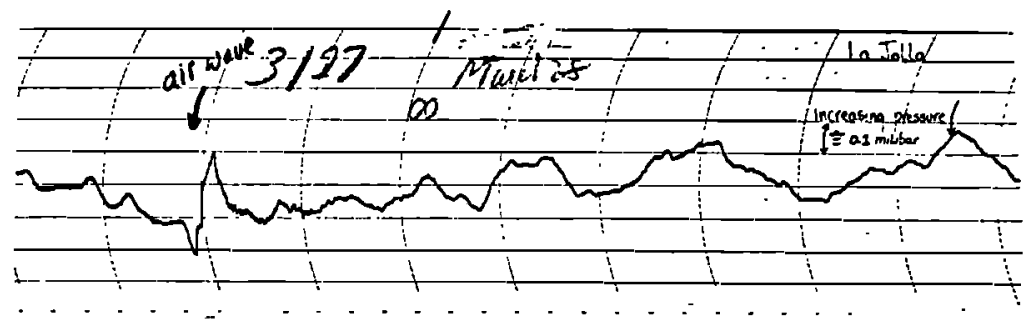

Fig. $3 b$.

Fig. 3. Microbarograms recorded at La Jolla, California (a) after Van Dorn [1964] and (b) provided by T. R. Madden. (The compression is downward.) 


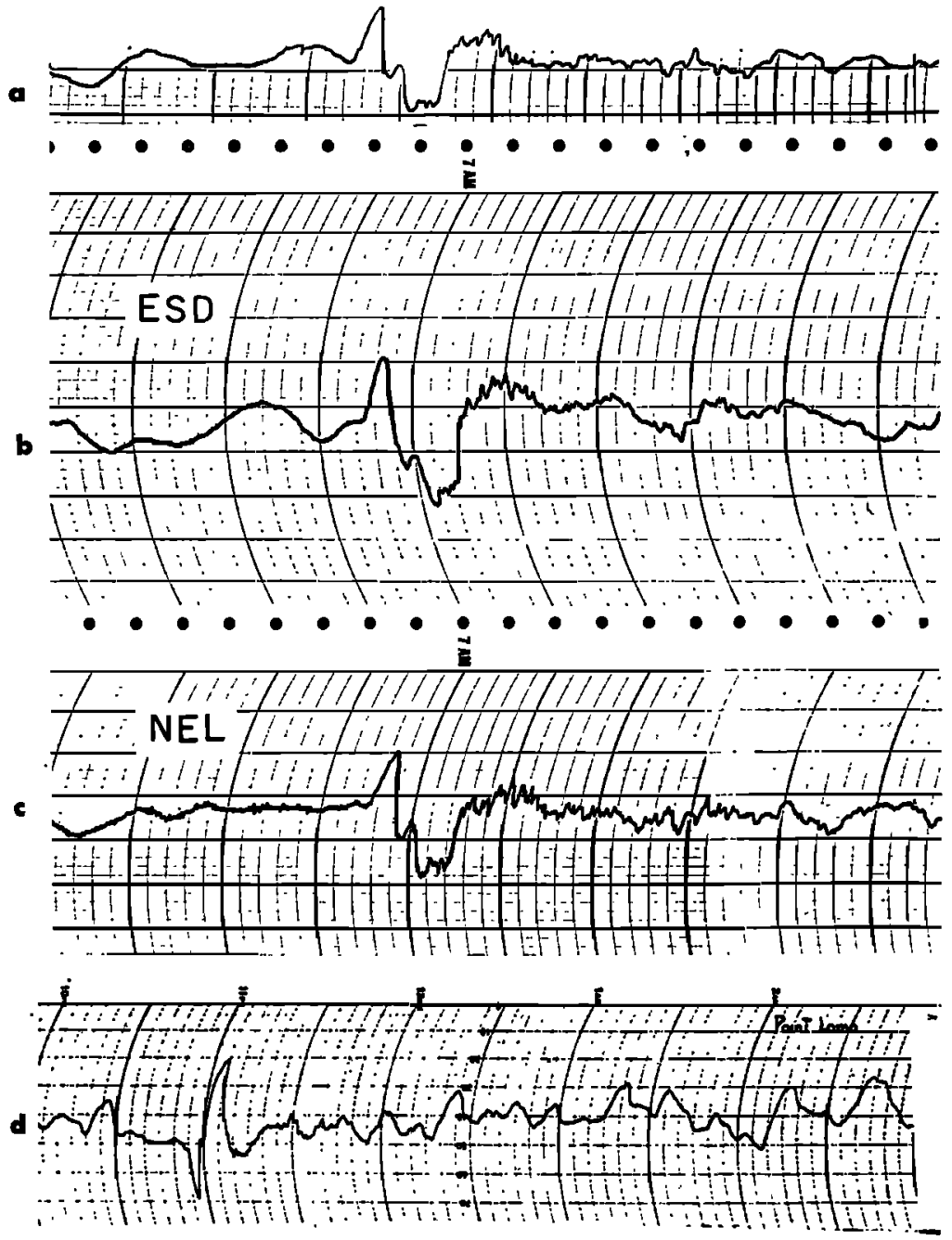

Fig. 4. Microbarograms recorded near San Diego. The maximum double amplitudes are about $50 \mu$ bar. (a) Mission Beach (MB); (b) East San Diego (ESD); (c) Point Loma (NEL); (d) Point Loma. Data for traces $a, b$, and $c$ were provided by C. T. Johnson; trace $d$, provided by T. R. Madden. (The compression is downward.)

TABLE 1. Location of Stations and Arrival Time of Pressure Waves

\begin{tabular}{lcccccc}
\hline \multicolumn{1}{c}{ Station } & $\begin{array}{c}\mathrm{N} \\
\text { Latitude }\end{array}$ & $\begin{array}{c}\mathrm{W} \\
\text { Longitude }\end{array}$ & $\begin{array}{c}\text { Epicentral } \\
\text { Distance, } \\
\mathrm{km}\end{array}$ & $\begin{array}{c}\text { Azimuth, } \\
\text { deg }\end{array}$ & $\begin{array}{c}\text { Arrival Time } \\
\text { of 1st Peak }\end{array}$ & $\begin{array}{c}\text { Sensitivity of } \\
\text { Microbarograph, } \\
\text { mm } / \mu \text { bar }\end{array}$ \\
\hline College & $6^{\circ} 52.0^{\prime}$ & $147^{\circ} 49.0^{\prime}$ & 382 & 359 & $03 \mathrm{~h} 57.2 \mathrm{~m}$ & 0.25 \\
Berkeley & $37^{\circ} 52.6^{\prime}$ & $122^{\circ} 14.1^{\prime}$ & 3127 & 135 & $06 \mathrm{~h} 18.7 \mathrm{~m}$ & 0.95 \\
La Jolla & $32^{\circ} 51^{\prime}$ & $117^{\circ} 15.2^{\prime}$ & 3827 & 131 & $06 \mathrm{~h} 56.8 \mathrm{~m}$ & $0.4 ?$ \\
Mission Beach & $32^{\circ} 47.4^{\prime}$ & $117^{\circ} 15.2^{\prime}$ & 3834 & 131 & $\mathbf{0 6 h} 56.5 \mathrm{~m}$ & 0.46 \\
E. San Diego & $32^{\circ} 45.9^{\prime}$ & $117^{\circ} 04.0^{\prime}$ & 3843 & 131 & $\mathbf{0 6 h} 57.7 \mathrm{~m}$ & 0.57 \\
Point Loma & $32^{\circ} 42.2^{\prime}$ & $117^{\circ} 14.3^{\prime}$ & 3842 & 131 & $\mathbf{0 6 h} 56.8 \mathrm{~m}$ & 0.48 \\
\hline
\end{tabular}




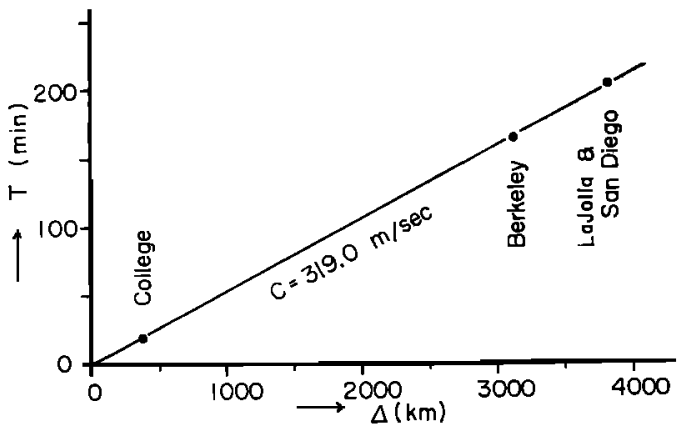

Fig. 5. Travel times of the first peak of the observed atmospheric waves.

sound velocity in the lower atmosphere and an intercept time nearly equal to zero. This relation suggests that the pressure disturbances now investigated were generated immediately after the earthquake near the source area and propagated as air waves.

\section{ANALYSIS}

Further analyses are made in this section to elucidate more detailed features of the recorded pressure waves. Bolt [1964] and Donn and Posmentier [1964] have estimated independently the group velocity of the waves from two records at Berkeley, but it seems rather difficult to determine a precise velocity directly from the original records because of their complicated wave forms with dispersive natures. For this reason, digital filtering has been applied here to the microbarograms from Berkeley, East San Diego, and College with the bandpass filters covering the three period ranges $1.75-3.5,3.5-$ 7.0 , and 7.0-14.0 min to separate shorter-, medium-, and longer-period components. If we use a simple box-car type filter having a response of $A(\omega)=A$ for $\omega_{0}-\omega_{0} \leq \omega \leq \omega_{0}+$ $\omega_{0}$ and otherwise $A(\omega)=0$, its impulse response $h(t)$ is given by, $h(t)=(2 A / \pi) \sin \left(\omega_{0} t\right) /$ $t \cdot \cos \omega_{0} t$. The output function or filtered record $g(t)$ can be obtained by the convolution of $h(t)$ with the original record $f(t)$,

$$
g(t)=\int f(t-\tau) h(\tau) d \tau
$$

The observed records were digitized at about 7 -sec intervals, and the above time integration was performed over the length of 2 hours. Figures 6 and 7 show the filtered records in the three period ranges for Berkeley and East San Diego, indicating a similar pattern for the corresponding traces, but the traces for College differ somewhat from the above two.

The group velocity can be determined from each of the filtered records at a single station by the customary method of using arrival times of successive trains. The waveform distortion that was introduced by filtering has been corrected before the time determination. Since Berkeley and East San Diego are almost on a great

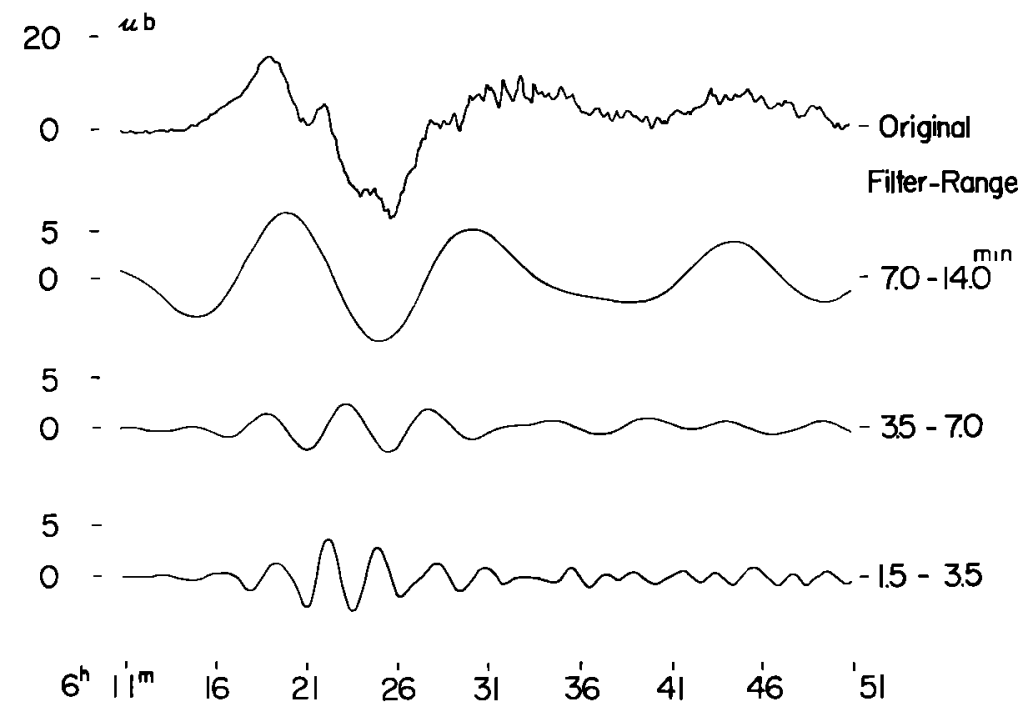

Fig. 6. Observed and filtered microbarograms for Berkeley. 


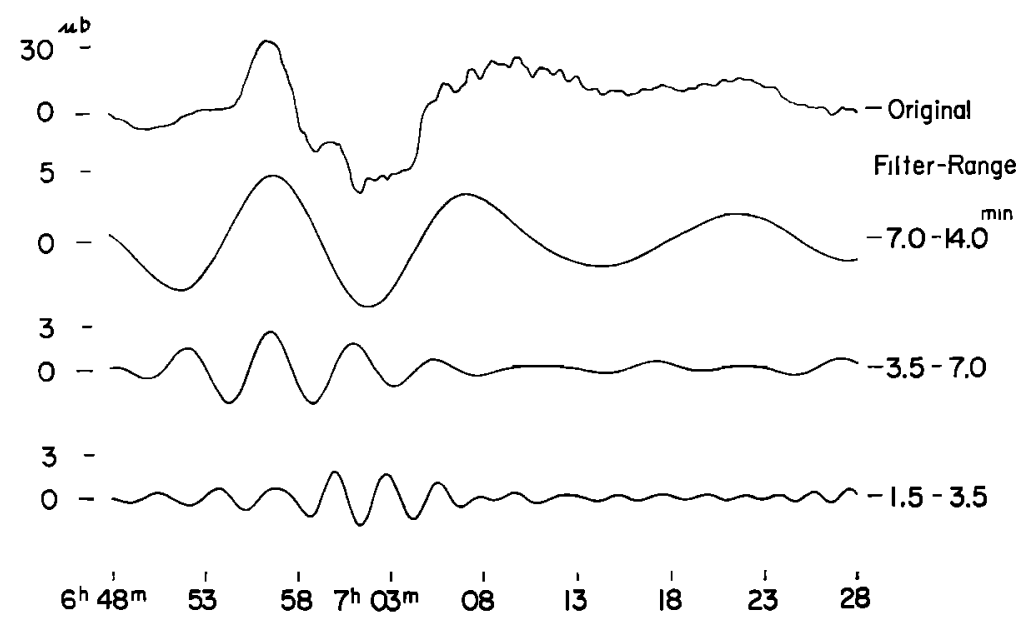

Fig. 7. Observed and filtered microbarograms for East San Diego.

circle path from the epicenter, direct time-delay measurements of coherent peaks and troughs on the corresponding filtered records also give the phase velocity for several periods. The group and phase velocities thus obtained are plotted in Figure 8 as a function of period, together with the theoretical dispersion curves of Press and Harkrider [1962] and Pfeffer and Zarichny [1963] for major acoustic-gravity modes. It appears that the measured velocities are consistent with those expected from their theory and agree well with past observations of nuclear explosions. The Fourier phase spectrum also provides information on the phase velocity. If pressure variations observed at a station can be expressed by

$$
f(t)=\frac{1}{\pi} \int_{0}^{\infty}|F(\omega)|[\cos \omega t+\varphi(\omega)] d \omega
$$

the difference in the Fourier phase between any two stations is

$$
\Delta \varphi(\omega)=\varphi_{2}(\omega)-\varphi_{1}(\omega)=\omega \Delta t=\omega \Delta r / C(\omega)
$$

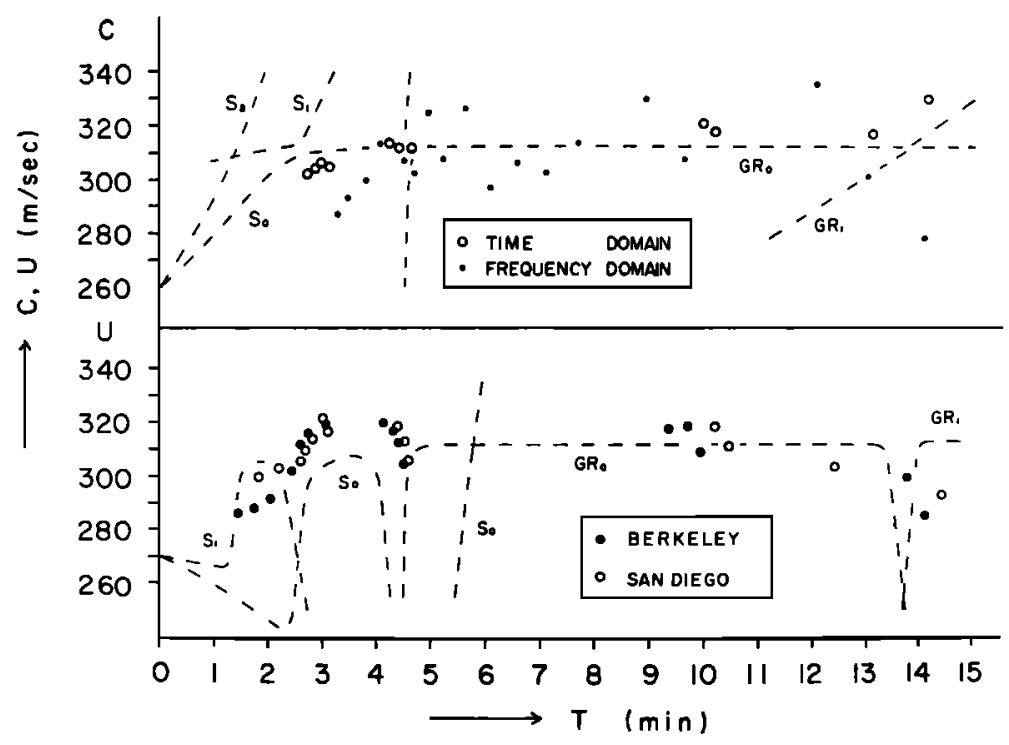

Fig. 8. Phase and group velocities of the pressure waves. 
The phase velocity should therefore be given by

$$
C(\omega)=\omega \Delta r /[2 N \pi-\Delta \varphi(\omega)]
$$

$[$ Satô, 1955], where $\Delta r$ is the difference in distance and $N$ is an integer that must be chosen to yield a consistent result. The records of Berkeley and East San Diego have been analyzed for this purpose by the Fourier transform over a time interval of $40 \mathrm{~min}$. The small dots plotted in Figure 8 are the phase velocities calculated by this method, if the same instrumental phase delay for the two stations is assumed. The results from the frequency domain scatter somewhat, as compared with those from the time domain analysis, but they would be improved by correlating more stations.

The amplitude and phase responses of microbarographs at three stations are illustrated in Figure 9. The responses for the Berkeley Seismographic Station instrument have been estimated theoretically (P. Rodgers, personal communication, 1966) and confirmed from the Fourier transform of a calibration record for a known step function. The responses for
College were determined by the latter method, but for East San Diego only the amplitude response has been supplied. The peak sensitivities are given in Table 1.

The amplitude spectra of the pressure waves, which have been corrected for the instrumental responses, are shown in Figure 10. As might be expected from the original records, spectral features for Berkeley and East San Diego give close agreement, having peaks around 13, 4-5 and $2.9 \mathrm{~min}$, respectively, but differ from those of College. The discrepancy for the last station may be explained by the short distance and different azimuth from the epicenter. The relative amplitude spectra in the period range up to 1 hour are shown in Figure 11. They were computed from the records at Berkeley (with time interval, 0400 hours March 28 to 0400 hours March 29), East San Diego (0400 hours March 28 to 0000 hours March 29), College (0500 hours March 28 to 0500 hours March 29), and Honolulu $\left(24.30^{\circ} \mathrm{N}, 158.09^{\circ} \mathrm{W} ; 0400\right.$ hours March 28 to 0400 hours March 29) to examine whether longer-period pressure oscillations would occur after the earthquake. Several strong

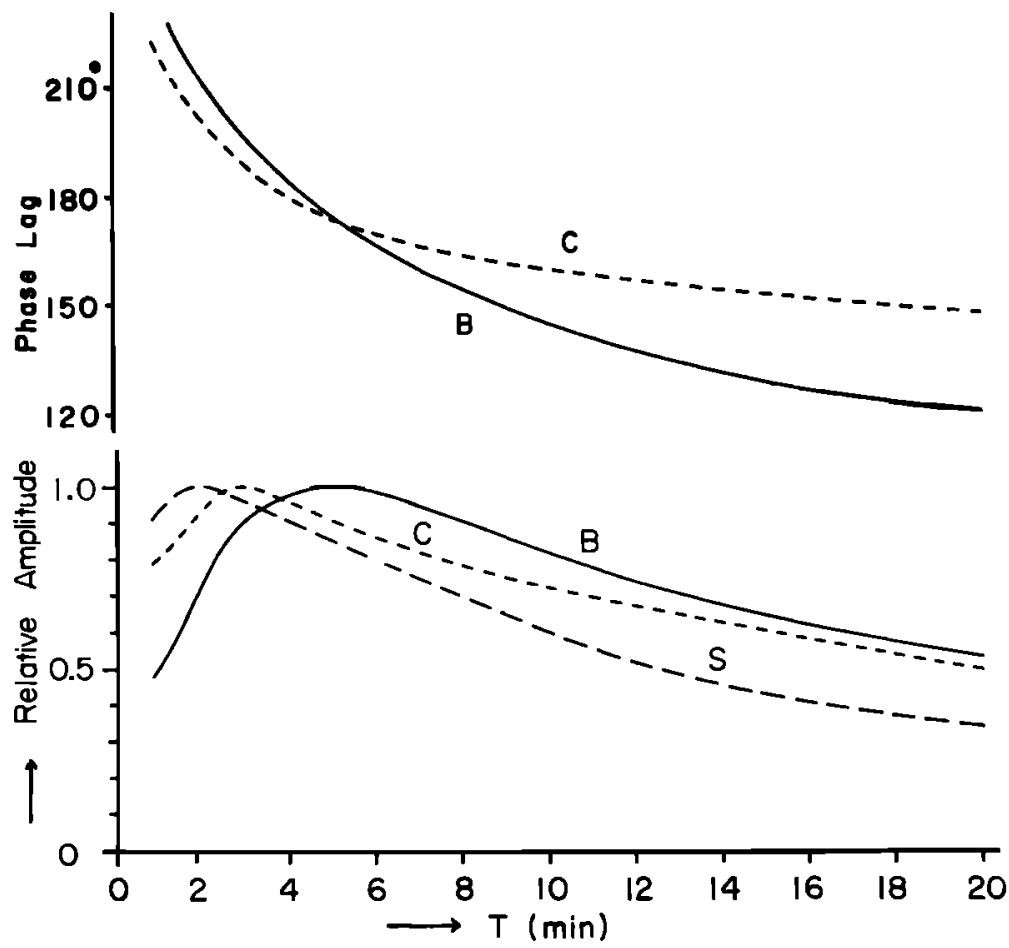

Fig. 9. Frequency response of microbarographs. B, Berkeley; S, East San Diego; C, College. 


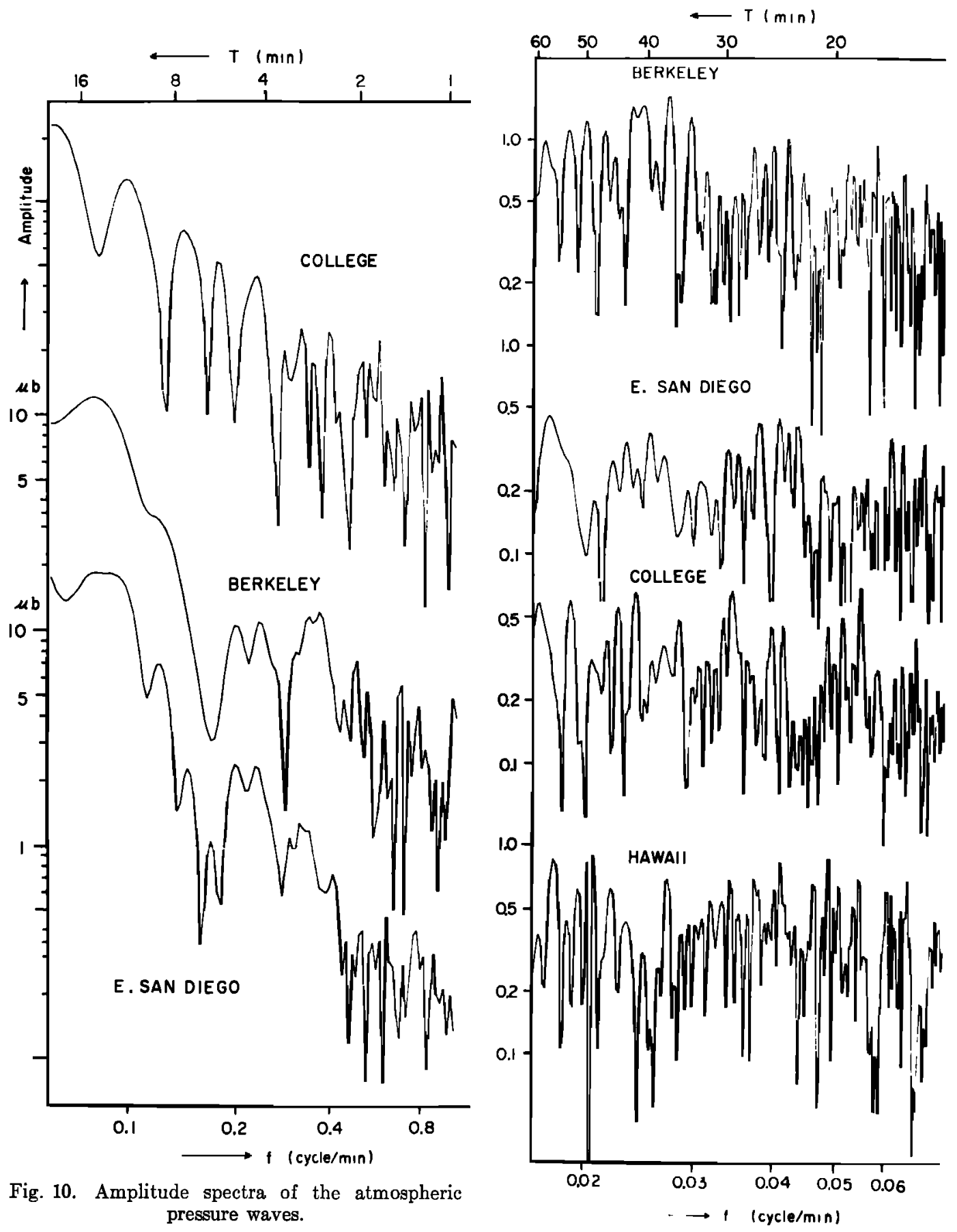

Fig. 11. Relative amplitude spectra in longperiod ranges. 
spectral peaks occur in that range, but the periods do not correlate among the four stations. This result means that most of them can be attributed to local pressure disturbances. If the observed atmospheric waves have been actually generated at the source, the amplitude spectra shown in Figure 10 should contain the effects of source mechanism, the response of the atmosphere, and the effects of mode interferences. Theoretical analysis of these effects is given in the next section.

Theoretical Consideration of Source Mechanism of Atmospheric Pressure Waves

The theory of pressure waves propagated in the atmosphere had been developed earlier in connection with the Krakatoa eruption and the great Siberian meteorite [Pekeris, 1948; Scorer, 1950] and later with nuclear explosions in the atmosphere [Yamamoto, 1957; Hunt et al., 1960 ; Weston, 1961]. The most complete theoretical studies attained in recent years are those of Pfeffer and Zarichny [1963], Press and Harkrider [1962], and Harkrider [1964], in which the phase and group velocity dispersion curves for various acoustic-gravity modes and, in some cases, theoretical barograms have been computed on the basis of realistic atmospheric models with multilayered structure. Some of the above studies included the effects of source altitude and source pressure function, but in all cases the source was assumed to be a simple point source. Striking differences in pressure waves of the Alaskan earthquake from those of nuclear explosions would be that the source may have a large dimension over the earth's surface and that the source pressure may be closely related to the vertical velocity of the ground movement.

The tectonic deformations that accompanied the earthquake have been surveyed from landleveling, tide-gage readings and some other measurements by the U. S. Geological Survey and the U. S. Coast and Geodetic Survey. The detailed map of the vertical tectonic movements compiled by Plafker [1965], as reproduced in Figure 12, shows that the major area of uplift, about $800 \mathrm{~km}$ long, extends northeast from

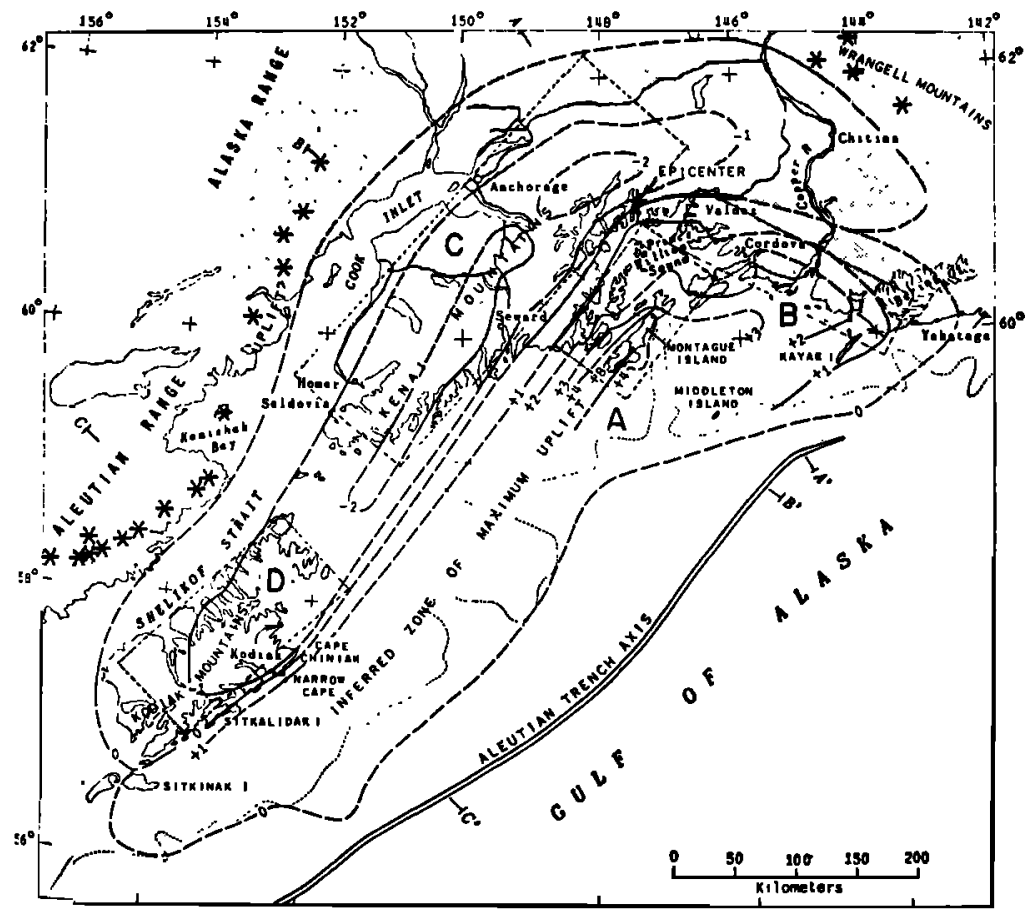

Fig. 12. Tectonic uplift and subsidence in south-central Alaska after the 1964 Alaskan earthquake, in which the land level change, in meters, is shown by the contours [after Plafker, 1965]. 
southern Kodiak Islands to Prince William Sound and east-west along the mainland coast, and that the zone of subsidence, approximately $800 \mathrm{~km}$ long and $150 \mathrm{~km}$ wide, includes most of the Kenai Peninsula and the Kodiak Islands. The maximum uplift reaches more than 10 meters on Montague Island. The zones of uplift. and subsidence may be divided into two large areas $\left(A^{\prime}\right.$ and $\left.B^{\prime}\right)$ including the Alaskan continental shelf, but we tentatively divide the principal zones on land into four rectangular regions, $A, B, C$, and $D$. Their dimension and the average amount of vertical displacement are given in Table 2. Taking these parameters into consideration, attempts are made to construct the theoretical barograms that would be recorded at Berkeley, for the purpose of explaining the major features of observed microbarogram.

Theory. Theoretical barograms from an explosive source at different altitudes have been fully given by Harkrider [1964], using a matrix formulation in which the vertical temperature structure of the atmosphere was represented by a large number of horizontally stratified isothermal layers. This paper follows his theoretical treatment with some modifications of the source parameters. (For symbols used without definition refer to Harkrider's [1964] paper.)

The source in the present case is distributed over the ground surface, so that $D$, source altitude in Harkrider's paper, may be taken as zero. We assume first that the ground motion has the form $J_{0}(k r) \cdot e^{i \omega t}$. The pressure perturbation $p_{s 0}$ and the upward particle velocity $w_{\text {so }}$ of the air at $z=0$ caused by the ground movement are related by [Harkrider, 1964]

$$
w_{\bullet 0}=\frac{i}{\omega \rho_{0} h_{0}}\left(\frac{\partial p_{s 0}}{\partial z}+\frac{g_{0}}{c_{0}{ }^{2}} p_{\bullet 0}\right)
$$

where $h_{0}=1-(\gamma-1) g_{0}{ }^{2} / \omega^{2} c_{0}{ }^{2}, \rho_{0}$ and $c_{0}$ are the ambient density and sound velocity near the ground, respectively, and $w_{\theta 0}$ should be connected with the vertical ground velocity, that is, $w_{s 0}=w_{g}=\dot{z}_{0}(r, t)$. Putting the general solution for the perturbation equation of $p_{s} 0$ into (1), we have an approximation for points close to the ground compared with wavelength

$$
p_{\mathrm{s} 0}(r, 0, t)=i \rho_{0} c_{0} f \dot{z}_{0}(r, t)
$$

where $f$ is a function of the ratio of the ground motion period to the local Brunt period $\left(T_{z}=\right.$
$2 \pi c_{0} / g_{0}(\gamma-1)^{1 / 2} \cong 340$ sec $)$, which takes values of $0.96,0.89$, and 0.84 for $T / T_{B}=0.1$, 0.3 , and 0.5 , respectively. The approximation by Donn and Posmentier [1964] $(f=1)$ may also be applied to the ground movement at the source if $T / T_{B}<0.3$. Since tectonic deformation includes a permanent displacement of the ground, $a$, it may be reasonable to assume that the ground displacement has the form

$$
z_{0}(r, t)=a\left(1-e^{-t / r}\right) H(t) \cdot J_{0}(k r)
$$

or

$$
\begin{gathered}
z_{0}(r, t)=\left(a / \tau^{\prime}\right) t \cdot H(t) \cdot J_{0}(k r) \\
\qquad \text { for } t<\tau^{\prime} \\
z_{0}(r, t)=a \text { for } t \geqq \tau^{\prime}
\end{gathered}
$$

If the source is confined within a circular region $(r \leqq b)$, the total flux of perturbation pressure introduced by the ground motion will be obtained by the integration of (2) in space and time:

$$
\begin{aligned}
\left\langle p_{s 0}\right\rangle_{T \mathbf{F}}= & \int_{-\infty}^{\infty} \int_{0}^{b} p_{s 0}(r, 0, t) r d r \cdot e^{-i \omega t} d t \\
= & i \rho_{0} c_{0} \int_{0}^{b} J_{0}(k r) r d r \\
& \cdot \int_{-\infty}^{\infty}(a / \tau) e^{-t / \tau} e^{-i \omega t} d t \\
= & \frac{i \rho_{0} c_{0} a}{1+i \omega \tau} \cdot \frac{b J_{1}(k b)}{k b}
\end{aligned}
$$

for the case of $(3 a)$. For distances large compared with the source dimension $(r \gg b)$, the solution for the pressure disturbance in the undermost layer will be

$$
\begin{aligned}
& \left\langle p_{\Delta 0}\right\rangle=\frac{i h_{0} \rho_{0} c_{0} a a_{s}}{1+i \omega \tau} e^{-\lambda_{0} z} \\
& \cdot \int_{0}^{\infty} \frac{\exp \left\{i k r_{\alpha 0} z\right\}}{i k r_{\alpha 0}} \cdot \frac{2 J_{1}(k b)}{k b} J_{0}(k r) k d k
\end{aligned}
$$

corresponding to Harkrider's equation 9.

To evaluate the pressure perturbations observed at great distances on the earth's surface, it is further necessary to compute the response of the atmosphere to the source. For a horizontally stratified atmosphere bounded on the top by an isothermal half-space and at the bottom by the rigid ground, three boundary 
TABLE 2. Major Regions of Tectonic Deformation

\begin{tabular}{|c|c|c|c|c|c|}
\hline \multirow[b]{2}{*}{ Region } & \multicolumn{2}{|c|}{ Dimension } & \multirow{2}{*}{$\begin{array}{c}\text { Distance to } \\
\text { Berkeley }\left(r_{0}\right) \text {, } \\
\text { km }\end{array}$} & \multirow{2}{*}{$\begin{array}{c}\text { Azimuth } \\
(\beta), \text { deg }\end{array}$} & \multirow{2}{*}{$\begin{array}{l}\text { Average Vertical } \\
\text { Displacement } \\
\qquad(a), \mathrm{m}\end{array}$} \\
\hline & $2 L, \mathrm{~km}$ & $2 W, \mathrm{~km}$ & & & \\
\hline$A$ & 120 & 80 & 3070 & 85 & +5.0 \\
\hline$B$ & 60 & 200 & 3000 & 73 & +1.5 \\
\hline$C$ & 350 & 120 & 3200 & 89 & -1.5 \\
\hline$D$ & 180 & 80 & 3170 & 101 & -1.0 \\
\hline$A^{\prime}$ & 300 & 160 & 3025 & 85 & +5.0 \\
\hline$B^{\prime}$ & 400 & 120 & 3190 & 85 & -1.5 \\
\hline
\end{tabular}

conditions are required: continuity of the vertical velocity and of total pressure at all interfaces of successive isothermal layers, $w_{1}(0)=0$ and $P_{p_{1}}(0)=p_{1}(0)=p_{0}$ at the ground surface except inside the source region, and the propagation constant of the $n$th layer $\Delta_{n}{ }^{\prime \prime}=0$. These conditions yield a matrix formulation for the atmospheric response. Following Harkrider's equations by letting $D$ approach zero, we obtain

$$
\begin{array}{r}
\left\langle p_{0}\right\rangle=\frac{i c_{0} a a_{s}}{\omega(1+i \omega \tau)} \cdot 2 \int_{0}^{\infty} \frac{N_{A}{ }^{(1)} N_{A}{ }^{(2)}}{F_{A}} \cdot \frac{2 J_{1}(k b)}{k b} \\
\cdot J_{0}(k r) k d k \quad(6)
\end{array}
$$

where $N_{4}{ }^{(1)}, N_{4}{ }^{(2)}$, and $F_{4}$ are functions of layer matrices. Quantities small compared to unity, which should be included in the above expression, have been omitted. Evaluation for the residue contribution of the integral solution yields the far-field solution

$$
\begin{gathered}
\left\{p_{0}\right\}_{A_{i}}=\frac{2 \pi c_{0} a a_{s}}{\omega(1+i \omega \tau)} k_{i}\left\{\left[\frac{p_{n-1}}{p_{0}}\right]_{H_{i}}\left(\frac{\partial F_{A}}{\partial k}\right)_{\omega, i}\right\}^{-1} \\
. \frac{2 J_{1}(k b)}{k b}\left(\frac{2}{\pi k_{i} r}\right)^{1 / 2}\left(\frac{r}{a_{\theta} \sin \theta}\right)^{1 / 2} e^{i\left(\omega t-k_{i} r+\pi / 4\right)}
\end{gathered}
$$

for each mode (or $k$, root of the period equation $F_{A}=0$ ), with an approximate curvature correction.

The pressure variation that would be recorded on a microbarogram may therefore be expressed by

$$
\begin{gathered}
{[p(r, 0, t)]_{A_{1}}=\frac{1}{2 \pi} \int_{-\infty}^{\infty}\left\{\rho_{0}\right\}_{A_{3}} B(\omega) e^{-i \varphi_{B}(\omega)} d \omega} \\
=\left(\frac{2}{\pi a_{0} \sin \theta}\right)^{1 / 2} \frac{a_{s}}{\rho_{0}} \cdot 2 \int_{0}^{\sigma_{1}} F(\omega)
\end{gathered}
$$

$$
\cdot \cos [\omega t-\varphi(\omega)] d \omega
$$

where

$$
F(\omega)=S(\omega) \cdot D(\omega) \cdot A(\omega) \cdot B(\omega)
$$

and

$\varphi(\omega)=\varphi_{S}(\omega)+\varphi_{D}(\omega)+\varphi_{A}(\omega)+\varphi_{B}(\omega)$

The source pressure function $S(\omega) \exp \left\{-i \varphi_{s}(\omega)\right\}$ is

$$
\begin{array}{ll}
S(\omega)=\frac{\rho_{0} c_{0} a}{\left(1+\omega^{2} \tau^{2}\right)^{1 / 2}} & (10 a) \\
S(\omega)=\rho_{0} c_{0} a \frac{\sin (\omega \tau / 2)}{\omega \tau / 2} & (10 b) \\
\varphi_{S}(\omega)=\tan ^{-1}(\omega \tau) \\
\varphi_{S}(\omega)=\omega \tau / 2
\end{array}
$$

corresponding to $(3 a)$ and $(3 b)$.

The source dimension factor $D(\omega) \exp \left\{-i \varphi_{D}\right.$ $(\omega)\}$ is written as

$$
D(\omega)=\frac{2 J_{1}(k b)}{k b} \quad \varphi_{D}(\omega)=0
$$

If the source is distributed with a uniform intensity over a rectangle (length $2 L$, width $2 W$ ), instead of a circular source, the integration in space would be $\iint p_{s 0}(r, 0, t) d x d y$. The distance $r$ from a surface element $d x \cdot d y$ to a distant point may be approximated by

$$
r \cong r_{0}-x \cos \beta+y \sin \beta
$$

where $\beta$ is the angle between the $x$ axis and the vector $\mathrm{r}$. If the distance dependence $J_{0}(k r)$ is replaced simply by exp ( $i k r)$, the integration without constants will be 


$$
\begin{aligned}
& \frac{1}{2 L \cdot 2 W} \iint \exp (i k r) d x d y \\
& =\frac{1}{2 L \cdot 2 W} \int_{-L}^{L} d x \int_{-W}^{W} \exp \left[i k \left(r_{0}-x\right.\right. \\
& \quad \cdot \cos \beta+y \sin \beta)] d y \\
& =\frac{\sin (k L \cos \beta)}{k L \cos \beta} \cdot \frac{\sin (k W \sin \beta)}{k W \sin \beta} \exp \left(i k r_{0}\right)
\end{aligned}
$$

so that

$$
D(\omega)=\left|\frac{\sin (k L \cos \beta)}{k L \cos \beta} \cdot \frac{\sin (k W \sin \beta)}{k W \sin \beta}\right|
$$

$\exp \left(i k r_{0}\right)$ is to be included in $A(\omega)$.

The atmospheric transfer function $A(\omega)$ $\exp \left\{-i \varphi_{\Delta}(\omega)\right\}$ is given by

$$
\begin{aligned}
A(\omega) & =A_{A_{i}}(\omega) k_{j}^{1 / 2} / \omega \\
\varphi_{A}(\omega) & =\frac{\omega r_{0}}{C_{i}(\omega)}-\frac{\pi}{4}
\end{aligned}
$$

and

$$
A_{A_{i}}(\omega)=\left\{\left[p_{n-1} / p_{0}\right]\left(\partial F_{A} / \partial k\right)_{\omega, j}\right\}^{-1}
$$

Harkrider has computed $A_{A},(\omega)$, the response of the atmosphere to a surface source and receiver, and the phase velocity $C_{f}(\omega)$ for the standard ARDC model of the atmosphere, which was approximated by thirty-nine isothermal layers terminated with an isothermal half-space at an elevation of $220 \mathrm{~km}$. These functions for major acoustic-gravity modes are reproduced in Figures 13 and 8 , respectively.

The barograph response $B(\omega) \exp \left\{-i \varphi_{B}(\omega)\right\}$ has been given in Figure 9. It is evident from equations 8-13 that the pressure variations of each mode depend on the source time function, source dimension, response of the atmosphere, and barograph response, and that recorded wave forms are a consequence of superposition of major acoustic-gravity modes.

Comparison between theoretical and observed barograms. We shall first compute theoretical barograms from a point source $(L=W=0)$, on the assumption that the source is confined to a limited area around the epicenter, small compared with the wavelength. To perform the Fourier synthesis Harkrider's equation 74 has been programmed. Figure 14 shows the barograms computed for the fundamental gravity mode $G R_{0}$, the fundamental, first, and second acoustic modes $S_{0}, S_{1}$, and $S_{2}$, respectively, with a tentative time constant of $\tau=0.3 \mathrm{~min}$. The bottom trace is the composite record of the four modes. In Figure 15 are illustrated the composite theoretical barograms with a variety of source functions. Although it is rather diffcult to evaluate the absolute amplitude for point-source models, the relative amplitudes for the various cases indicate that as the ground moves more slowly, the resulted amplitude diminishes with the decay of shorter-period components. It does not appear, however, that the features of the Berkeley record can be accounted for by the modifications of the source time function for a point source.

The next step is to introduce the source dimension and the average amount of the ground displacement on the principal regions, given in

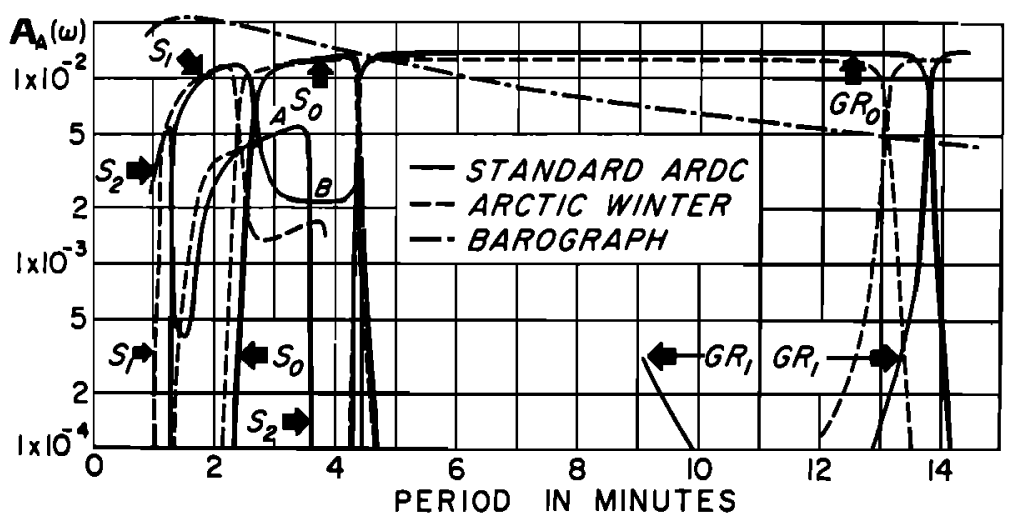

Fig. 13. Spectral amplitude of $A_{\Lambda}(\omega)$ for the ARDC standard and arctic winter atmosphere [after Harkrider, 1964]. 

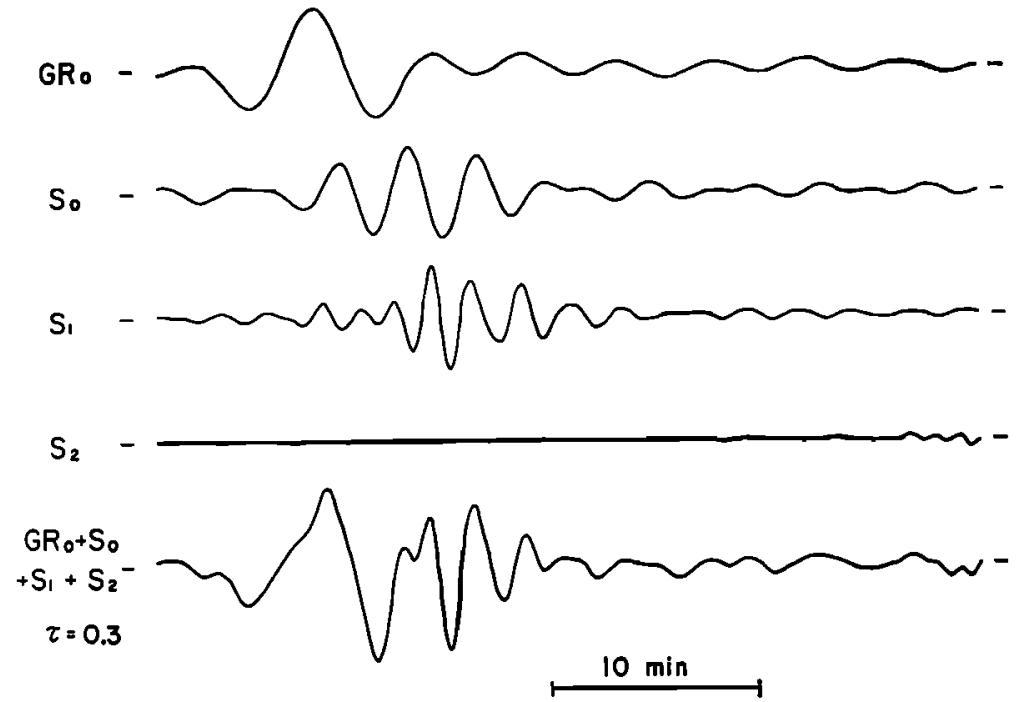

Fig. 14. Theoretical barograms for major acoustic-gravity modes from a point-source model.

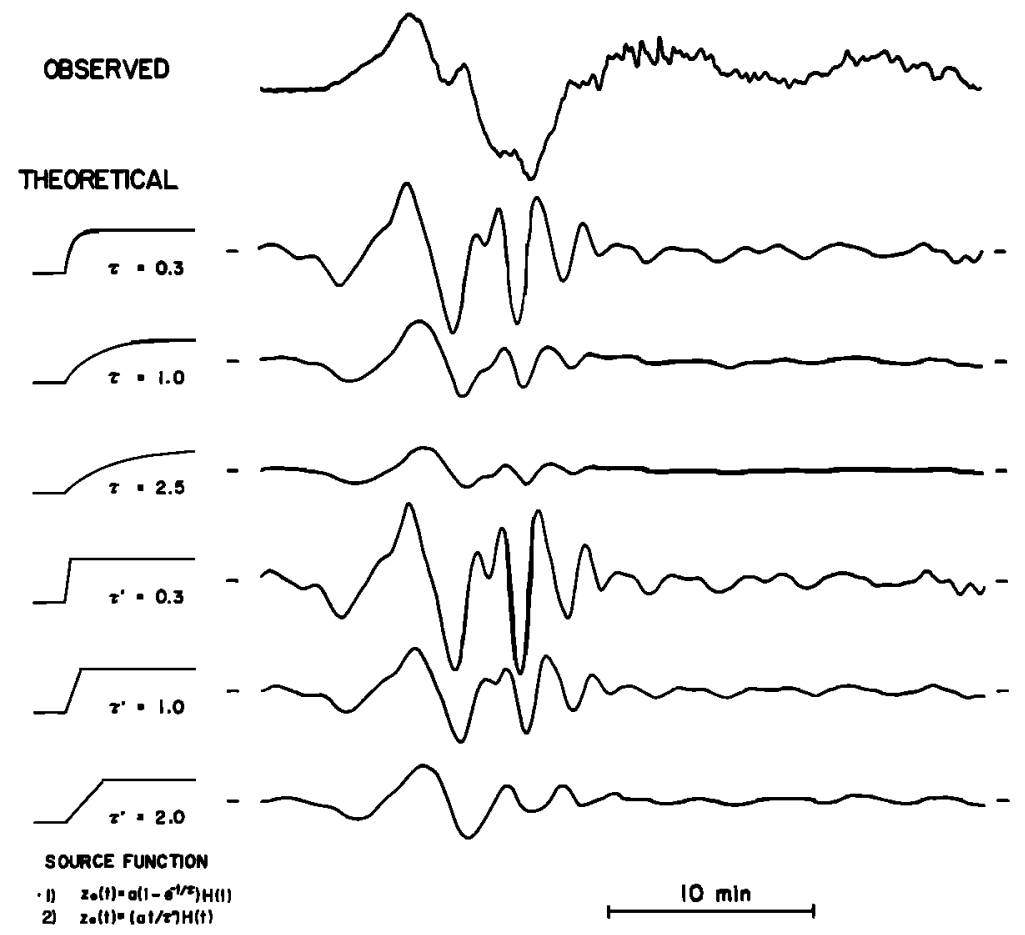

Fig. 15. Theoretical barograms from a point-source model with various source functions and the observed Berkeley microbarogram. 
Table 2, into equations 12 and 10 . Figure 16 shows the theoretical barograms, including four major modes, produced by the vertical ground displacement of a step function type in the four regions, $A, B, C$, and $D$. The relative amplitudes are multiplied by the area $(4 L W)$ of the corresponding region, since the outgoing energy of the pressure waves may be proportional to the volume of the air mass disturbed by the ground movement. The phase difference in a main pulse among the four traces is due to the difference in the epicentral distances from the center of each region to station. None of the four traces gives a satisfactory agreement with the observed barogram, even if allowance is made for the absolute time difference. If we assume that the ground movement has occurred at the same time after the earthquake in all the regions with the same type of source function, the synthetic barogram would be a simple superposition of the four traces for the corresponding regions, as shown by the lowest trace. The time rates of the ground displacement are not known accurately, but it is likely that much of tectonic deformation has been completed within 1.5-4 min or a little longer, since immediate withdrawals of water from uplifted coastal regions were reported by many observers [Van Dorn, 1964; Plafker, 1965]. Figure 17 gives the synthetic theoretical barograms for the variations in the time constant of the source function from 0 to $1 \mathrm{~min}$, with the same assumption as above for the initial movement time. It may be seen in the figure that the main features of theoretical wave forms except $A^{\prime}+B^{\prime}$ are in good agreement with those of the Berkeley microbarogram, although their arrival times have been so adjusted to make it easy to compare the two kinds of barograms.

Discussion. Closer examinations of the theoretical traces shows, however, the presence of a large dilatation precursor and the lack of periods shorter than 2 min. The dilatation precursor may be due to truncation of the synthesis at a period near $14 \mathrm{~min}$. The theoretical phase of long waves also indicates a slight advance to the observed phase, but this might be attributable partly to the assumption for simultaneous occurrence of the displacements at the four regions. There is a possibility that some of the discrepancies between the theoretical and the observed barograms could be reconciled by small modifications of the atmospheric model adopted. An alternative introduced here is a standard ARDC atmosphere terminated at an altitude of $220 \mathrm{~km}$ with a free surface instead of an isothermal half-space [Press and Harkrider, 1962; Harkrider and Press, 1967] for which there is no long-period cutoff. Similar computations with $\tau=0.3 \mathrm{~min}$ give the syn-

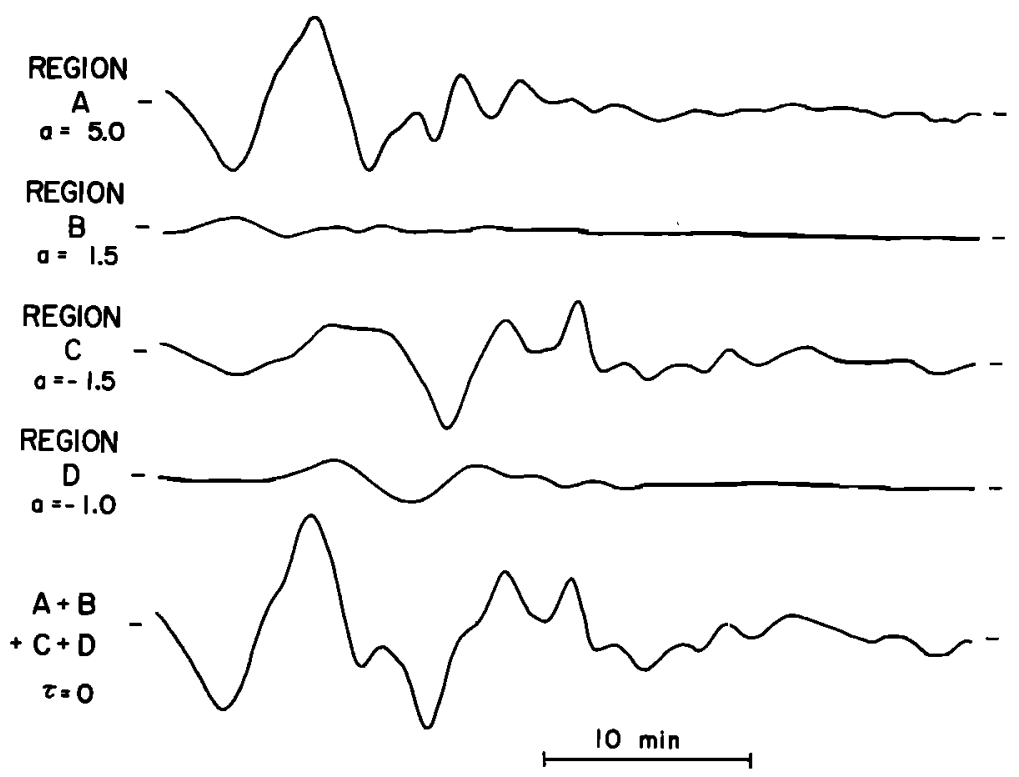

Fig. 16. Theoretical barograms from four finite source regions. 


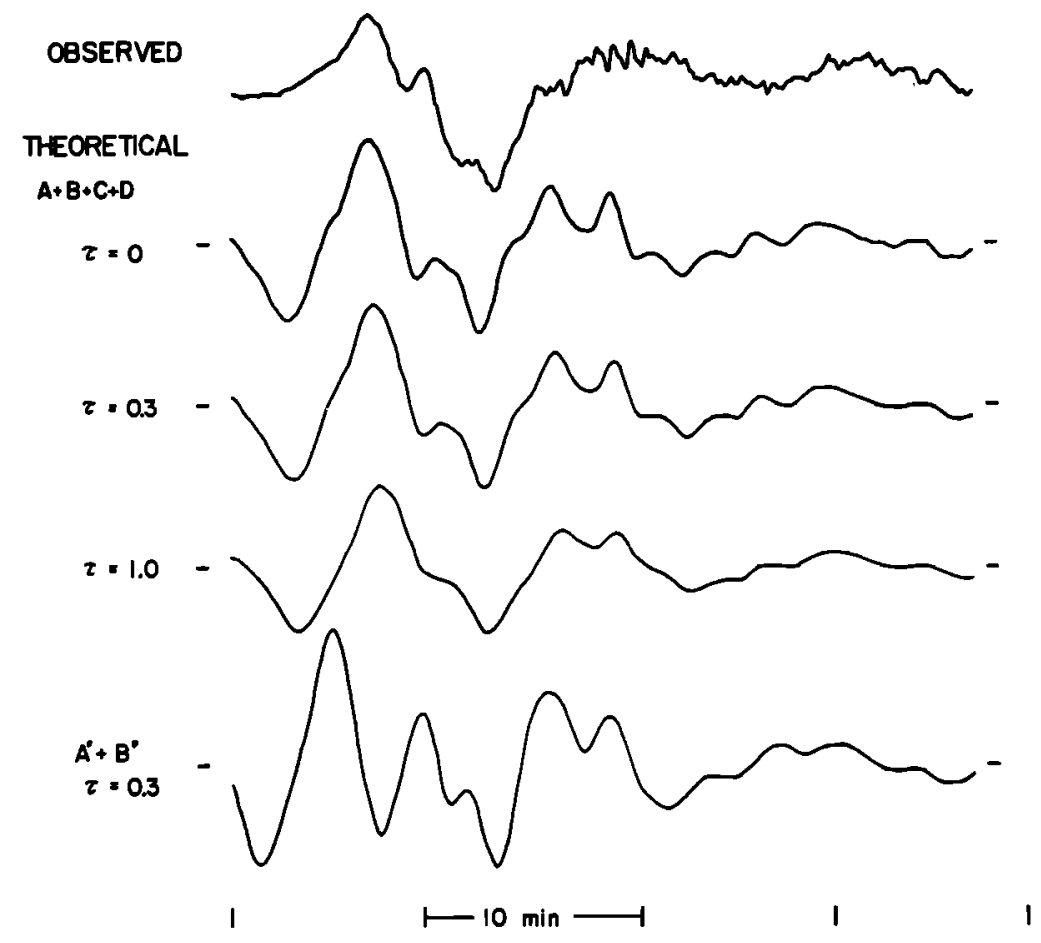

Fig. 17. Synthetic theoretical barograms with various source functions and the Berkeley microbarograms.

thetic barogram as shown in Figure 18c. The theoretical trace $(c)$ does not indicate the large dilatation precursor as seen in (a) for the foregoing model but loses long-period coda waves. The trace $(b)$ has been tentatively computed from a hypothetical atmospheric model with a period cutoff at $20 \mathrm{~min}$. This will correspond to an atmosphere with a free surface at an altitude higher than $220 \mathrm{~km}$. As would be expected, the features of the wave form $(b)$ lie between $(a)$ and $(c)$. There still remain some discrepancies between the theoretical trace $(b)$ or (c) and the observed barogram. A more complete atmospheric model with temperaturewind structure might give better results. In spite of the minor differences, the general agreement between the theoretical prediction and the observation manifested in Figure 17 or 18 appears to give a strong support to the hypothesis that the vertical ground movement mainly in the four regions may be a possible source of the atmospheric pressure waves now considered.

The last trace in Figure 17 was computed from the two source regions $B^{\prime}$, the zone of subsidence almost identical with $C$ region, and $A^{\prime}$, an inferred uplift zone covering a large oceanic area, on the assumption that the sea surface moves in the same behavior as the solid land was elevated. The consistency between the trace and the observed record is not so good as in the case of $A+B+C+D$ and was not much improved by the modifications of atmospheric model. This situation suggests either that the elevation of the offshore zone $A^{\prime}$ took place with a somewhat different time rate from that of the subsidence of the land $B^{\prime}$, or that there was a phase difference in the motion between the source areas (Wm. G. Van Dorn, personal communication, 1967). The short-period (1.0$1.5 \mathrm{~min}$ ) disturbances as superposed on longperiod waves on the microbarograms from Berkeley and East San Diego do not appear on any of the theoretical traces. The disturbances are identified, however, as traveling waves with a sound velocity of $314 \mathrm{~m} / \mathrm{sec}$, which yields a time difference of about $38 \mathrm{~min}$ between the two stations. The evidence, together with their time delay of about $16 \mathrm{~min}$ from the onset of 
(a)

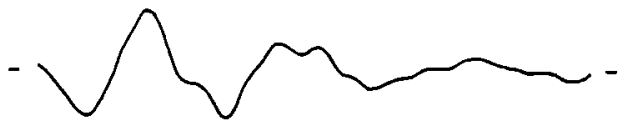

(b)

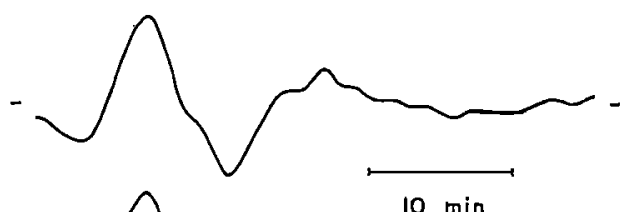

(c)

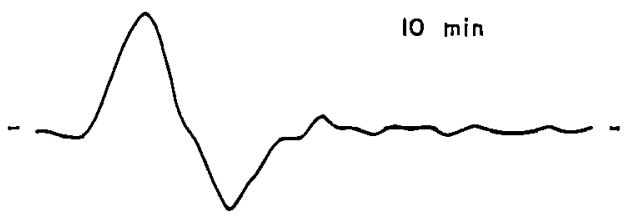

Fig. 18. Synthetic theoretical barograms with different atmospheric models. (a) The standard model terminated with an isothermal half-space at an altitude of $220 \mathrm{~km}$. (b) The standard model with a hypothetical period cutoff at $20 \mathrm{~min}$. (c) The standard model terminated with a free surface at an altitude of $220 \mathrm{~km}$.

long-period waves, suggests that the shortperiod waves might have been excited by a secondary source movement, such as the seiche of water and tsunamis around the oceanic source area.

The absolute amplitude of synthetic theoretical barograms may be roughly evaluated by summing all major modes and weighting each of the source areas to equation 8 . The pressure perturbation in the source region may be of an order of a millibar according to equation 2 with values of $\rho_{0}=1.293 \times 10^{-3} \mathrm{~g} / \mathrm{cm}^{3}, c_{0}=330 \mathrm{~m} /$ sec, and $a=5$ meters. There remains an ambiguity for the scaling distance $a_{s}$. This distance may be regarded as an upper level below which the approximate relation (2) holds. If we assume that equation 8 can roughly be applied also to the pressure variations at shorter distances, the maximum double amplitude of $124 \mu$ bar for the long waves observed at College, which assigns about 100 meters to $a_{s}$, should produce the corresponding amplitude of $45 \mu$ bar for Berkeley. This value compares well with the observed value of $40 \mu \mathrm{bar}$. More exact estimates cannot be made unless other factors that could have some importance, such as seasonal variations of atmospheric temperature structure, prevailing wind velociy and dissipation effects, are taken into account.

The uncertainty in absolute amplitudes and small differences in the wave forms between theoretical barograms with different time constants could not provide a definite information on the time rate of ground deformation at the source. It is to be noted, however, that the condition that $\tau$ is much greater than 1 min introduces considerable inconsistencies between the theoretical and the observed records. This really implies that the deformation does not seem to have lasted much longer than $3 \mathrm{~min}$. We come to the conclusion that large-scale ground deformations that accompany a destructive earthquake of the order of the Alaskan earthquake could generate atmospheric pressure waves that could be observed at long distances, and that a possible time rate of the surface deformations could be estimated from the observations under favorable circumstances.

Acknowledgments. The earlier part of the present work was made at the Seismographic Station of the University of California, Berkeley. I am grateful to Professor Bruce A. Bolt for his original suggestions to this study and critical review of the manuscript. Professor Ryozaburo Yamamoto, the Geophysical Institute of Kyoto University, gave helpful discussions on the theoretical sides. I wish to express my gratitude to Dr. David G. Harkrider, Brown University, and Dr. Wm. G. Van Dorn, Scripps Institution of Oceanography of the University of California, San Diego, for their valuable comments on the manuscript. The following persons kindly provided or surveyed microbarograph records obtained at their stations: Professor Eduard Berg, Geophysical Institute of the University of Alaska, Professor Theodore R. Madden, Massachusetts Institute of Technology, Drs. Charles T. Johnson and Earl Gossard, the U.S. Navy Electronics Laboratory, San Diego, Dr. William L. Donn, Lamont Geological Observatory of Columbia University, Professor J. Cl. De Bremaecker, Rice University, Dr. Nobuhiko Murayama, the Japan Meteorological Agency, Directors of the U.S. Weather Record Center, ESSA, the Canadian Air Services, and Department of Oceanography of Oregon State University. Dr. Peter Rodgers provided his theoretical response curves of the Berkeley microbarograph. My particular thanks are also due Mrs. Ritsuko Koizumi for assistance in the analysis of the microbarograph records.

The numerical computations involved were made partly on an IBM 7090 through the UNICON and partly by a HITAC 5020 at the Computation Center, University of Tokyo.

\section{ReFeRENCES}

Benioff, H., M. Ewing, and F. Press, Sound waves in the atmosphere generated by a small earthquake, Proc. Natl. Acad. Sci. U.S., 37, 600, 1951. Benioff, H., and B. Gutenberg, Waves and currents 
recorded by electromagnetic barographs, Bull. Am. Meteorol. Soc., 20, 421, 1939.

Bolt, B. A., Seismic air waves from the great 1964 Alaskan earthquake, Nature, 202, 1095, 1964.

Donn, W. L., and M. Ewing, Atmospheric waves from nuclear explosions, J. Geophys. Res., 6\%, $1855,1962$.

Donn, W. L., and E. S. Posmentier, Groundcoupled air waves from the great Alaskan earthquake, J. Geophys. Res., 69, 5357, 1964.

Donn, W. L., and D. M. Shaw, Exploring the atmosphere with nuclear explosions, Rev. Geophys., 5, 53, 1967.

Harkrider, D. G., Theoretical and observed acoustic-gravity waves from explosive sources in the atmosphere, J. Geophys. Res., 69, 5295, 1964.

Harkrider, D. G., and F. Press, The Krakatoa air-sea waves: An example of pulse propagation in coupled systems, Geophys. $J ., 13,149,1967$.

Hunt, J. N., R. Palmer, and W. Penney, Atmospheric waves caused by large explosions, Phil. Trans. Roy. Soc., London, A, 25\%, 275, 1960.

Pekeris, C. L., The propagation of a pulse in the atmosphere, 2, Phys. Rev., 78, 145, 1948.

Pfeffer, R. L., and J. Zarichny, Acoustic-gravity wave propagation in an atmosphere with two sound channels, Geofis. Pura. Appl., 65, 175, 1963.

Plafker, G., Tectonic deformation associated with the 1964 Alaskan earthquake, Science, 148, 1675, 1965.
Press, F., and D. G. Harkrider, Propagation of acoustic-gravity, waves in the atmosphere, $J$. Geophys. Res., 67, 3889, 1962.

Row, R. V., Atmospheric waves related to the Alaskan earthquake of 28 March 1964, Res. Rept. 525, Sylvania Appl. Res. Lab., 1967.

Satô, Y., Analysis of dispersed surface waves by means of Fourier transform, 1, Bull. Earthquake Res. Inst. Tokyo Univ., 33, 33, 1955.

Scorer, R. S., The dispersion of a pressure pulse in the atmosphere, Proc. Roy. Soc., London, A, 201, 137, 1950.

Van Dorn, Wm. G., Source mechanism of the tsunami of March 28, 1964, in Alaska, Proc. 9th Conf. Coastal Engr., Am. Soc. Civil Engr., 166, 1964.

Weston, V. H., The pressure pulse produced by a large explosion in the atmosphere, Can.J. Phys., 39, 993, 1961.

Yamamoto, $\mathbf{R}$., The microbarographic oscillations produced by the explosions of hydrogen bombs in the Marshall Islands, Weather, 10, 321, 1955.

Yamamoto, R., A dynamical theory of the microbarographic oscillations produced by the explosions of hydrogen bombs, J. Meteorol. Soc. Japan, $35,32,1957$.

(Received September 25, 1967.) 